\title{
Reversible dehydrogenation and rehydrogenation of cyclohexane and methylcyclohexane by single- site platinum catalyst
}

Luning Chen ${ }^{1,2,3,8}$, Pragya Verma ${ }^{1,8}$, Kaipeng Hou ${ }^{4,8}$, Zhiyuan $\mathrm{Qi}^{3}$, Shuchen Zhang ${ }^{3}$, Yi-Sheng Liu (1) ${ }^{5}$, Jinghua Guo (1) 5, Vitalie Stavila (10 6 , Mark D. Allendorf (1) ${ }^{6}$, Lansun Zheng ${ }^{2}$, Miquel Salmeron (1) 3,7, David Prendergast (1) ${ }^{1 \times}$, Gabor A. Somorjai (i) ${ }^{3,4 凶} \&$ Ji Su (iD) ${ }^{1,3 凶}$

Developing highly efficient and reversible hydrogenation-dehydrogenation catalysts shows great promise for hydrogen storage technologies with highly desirable economic and ecological benefits. Herein, we show that reaction sites consisting of single $\mathrm{Pt}$ atoms and neighboring oxygen vacancies $\left(\mathrm{V}_{\mathrm{O}}\right)$ can be prepared on $\mathrm{CeO}_{2}\left(\mathrm{Pt}_{1} / \mathrm{CeO}_{2}\right)$ with unique catalytic properties for the reversible dehydrogenation and rehydrogenation of large molecules such as cyclohexane and methylcyclohexane. Specifically, we find that the dehydrogenation rate of cyclohexane and methylcyclohexane on such sites can reach values above 32,000 $\mathrm{mol}_{\mathrm{H} 2}$ mol $_{\mathrm{Pt}}^{-1} \mathrm{~h}^{-1}$, which is 309 times higher than that of conventional supported $\mathrm{Pt}$ nanoparticles. Combining of DRIFTS, AP-XPS, EXAFS, and DFT calculations, we show that the $\mathrm{Pt}_{1} / \mathrm{CeO}_{2}$ catalyst exhibits a super-synergistic effect between the catalytic Pt atom and its support, involving redox coupling between Pt and Ce ions, enabling adsorption, activation and reaction of large molecules with sufficient versatility to drive abstraction/addition of hydrogen without requiring multiple reaction sites.

\footnotetext{
${ }^{1}$ The Molecular Foundry, Lawrence Berkeley National Laboratory, Berkeley, CA 94720, USA. ${ }^{2}$ State Key Laboratory of Physical Chemistry of Solid Surfaces, Collaborative Innovation Center of Chemistry for Energy Materials, and Department of Chemistry, College of Chemistry and Chemical Engineering, Xiamen University, 361005 Xiamen, China. ${ }^{3}$ Chemical Sciences Division, Lawrence Berkeley National Laboratory, Berkeley, CA 94720, USA. ${ }^{4}$ Department of Chemistry, University of California-Berkeley, Berkeley, CA 94720, USA. ${ }^{5}$ Advanced Light Source, Lawrence Berkeley National Laboratory, Berkeley, CA 94720, USA. ${ }^{6}$ Sandia National Laboratories, Livermore, CA 94551, USA. ${ }^{7}$ Materials Science and Engineering Department, University of California-Berkeley,

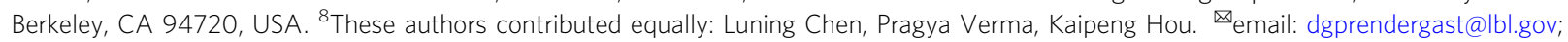
somorjai@berkeley.edu; jisu@lbl.gov
} 
M etal particles on various supports play a central role in energy conversion reactions and chemical transformations by heterogeneous catalysis. Ideally, the support immobilizes the particles reducing their mobility to prevent sintering, and favoring chemical stabilization ${ }^{1}$. Active supports, consisting of reducible oxides participate in the catalytic reaction through metal-support interactions involving charge transfer between metal particles and support, harboring multi-functional active centers, and mediating spillover of reactants and products $^{2-4}$. Recently, the creation of single-site catalysts ${ }^{5-7}$, where single metal atoms are anchored on support by bonding to ligands such as $\mathrm{N}$ or $\mathrm{O}$, has opened up a new research frontier in the catalysis field ${ }^{8-10}$. The isolated metal sites provide a bridge between heterogeneous and homogeneous catalysis ${ }^{11}$. Reduction of the size of metal nanoparticles down to a single atom achieves the maximum efficiency of utilization of expensive noble metals, with gains in activity, stability, and selectivity ${ }^{12-14}$. However, the lack of an ensemble of other active sites adjacent to the single noble metal atom may prevent surface reactions that involve large molecules ${ }^{15,16}$. Recent studies demonstrated that "ensemble effects" between the single metal atom and neighboring oxygen vacancies can favor oxygen transfer and adsorption of reactants, enabling catalysis reactions of the functional groups on large molecules with higher efficiency ${ }^{17-19}$. The beneficial effect of oxygen vacancy sites next to the noble metal ${ }^{12,14}$ motivated us to further explore its possibilities with the goal to discover new reactions and to accelerate the development of next-generation single-site catalysts.

Hydrogen is an ideal fuel for clean energy, replacing traditional hydrocarbon feedstocks. It is also used in polymer electrolyte membrane fuel cells (PEMFCs) because of its high mass-energy density of $141.6 \mathrm{MJ} / \mathrm{kg}$, three times higher than that of gasoline, while producing water as the only by-product ${ }^{20-22}$. The challenges of these applications are associated with the difficulties of efficient hydrogen storage, which today are mostly based on compression and liquefaction technologies, introducing safety concerns and low storage density, as well as transportation, boiloff losses, and other high-cost problems ${ }^{23}$. Liquid organic hydrogen carriers (LOHCs) represent an attractive alternative to store hydrogen in chemical bonds and can address a number of limitations of present technologies ${ }^{24}$. Reversible LOHC systems are always composed of pairs of hydrogen-poor and hydrogenrich organic compounds that store hydrogen by hydrogenation and dehydrogenation ${ }^{25}$, which has a high potential for mobile applications ${ }^{26}$. Cycloalkanes and aromatics with one or more sixmembered rings are promising reversible LOHC systems. These stable compounds have high storage capacities (between 6 and 7 wt.\% $\mathrm{H}_{2}$ ) and can be dehydrogenated/rehydrogenated under relatively mild conditions ${ }^{27,28}$. Supported Pt nanoparticle catalysts are industrially mature and superior heterogeneous catalysts used in hydrocarbon refineries ${ }^{29,30}$. Based on a sulfated $\mathrm{Pt}$ nanoparticle catalyst $\left(\mathrm{S}-\mathrm{Pt} / \mathrm{Al}_{2} \mathrm{O}_{3}\right)$, Chiyoda Corporation developed a LOHC system with dehydrogenation/rehydrogenation of methylcyclohexane $(\mathrm{MCH}) /$ toluene and demonstrated its feasibility and advantage for hydrogen storage and transportation ${ }^{31}$. Nevertheless, the high cost and low natural abundance of $\mathrm{Pt}$ limited its further application. Downsizing of Pt from nanoparticle to single atoms is an effective method to maximize the $\mathrm{Pt}$ atom efficiency and reduce this component of the capital investment.

In this work, we show the successful fabrication and demonstration of isolated single $\mathrm{Pt}$ atoms on $\mathrm{CeO}_{2}\left(\mathrm{Pt}_{1} / \mathrm{CeO}_{2}\right)$ that is highly efficient and reversible for dehydrogenation/rehydrogenation of large cyclic hydrocarbons. As we will show, compared with traditional Pt nanoparticle catalysts (several $\mathrm{nm}$ in size on $\mathrm{CeO}_{2}$ ), the single $\mathrm{Pt}$ atom catalyst displays significantly higher catalytic performance for both dehydrogenation and rehydrogenation reactions. In particular, the turnover frequency (TOF) of cyclohexane and methylcyclohexane on such single Pt sites could reach $>32,000 \mathrm{~mol} \mathrm{H}_{2}$ per mol Pt per hour $\left(5.5 \mathrm{~g}_{\mathrm{H} 2}\right.$ $\left.\mathrm{g}_{\mathrm{Pt}}{ }^{-1} \mathrm{~min}^{-1}\right)$, which is 309 times that of commercial $\mathrm{Pt} / \mathrm{Al}_{2} \mathrm{O}_{3}$ (5 wt.\%) catalyst. Key to this high performance is the discovery that oxygen vacancies next to the Pt atom site facilitate adsorption of these large cyclic molecules and stepwise dehydrogenation reactions driven by a super-synergistic effect involving redox coupling between $\mathrm{Pt}$ and $\mathrm{Ce}$ atoms.

\section{Results and discussion}

Preparation and characterization of isolated single $\mathrm{Pt}$ sites on $\mathrm{CeO}_{2}\left(\mathrm{Pt}_{1} / \mathrm{CeO}_{2}\right)$. The $\mathrm{Pt}_{1} / \mathrm{CeO}_{2}$ catalyst was fabricated by a modified ascorbic acid (AA)-assisted reduction method, described in detail in the methods section ${ }^{32}$. Porous $\mathrm{CeO}_{2}$ nanorods were synthesized and employed as supports to isolate $\mathrm{Pt}$ single sites due to their high specific area. Inductively Coupled Plasma Optical Emission Spectroscopy (ICP-OES) measurements revealed that the final content of $\mathrm{Pt}$ was $0.15 \mathrm{wt} . \%$.

After deposition of $\mathrm{Pt}$ on $\mathrm{CeO}_{2}$, no peaks from $\mathrm{Pt}$ were observed in the powder X-ray diffraction (XRD) pattern, due to the low Pt content and small size of the particles that may be present (Supplementary Fig. 1). Moreover, no difference was observed, relative to the original $\mathrm{CeO}_{2}$ nanorods, in bright-field transmission electron microscopy (TEM) images, indicating that the number of such Pt nanoparticles or clusters is below the detection limit (Supplementary Fig. 1). However, elemental mapping of $\mathrm{Pt}_{1} / \mathrm{CeO}_{2}$ catalyst by HAADF-STEM, shows that $\mathrm{Pt}$ is present and uniformly distributed on the $\mathrm{CeO}_{2}$ nanorods (Fig. 1a). More importantly, Cs-corrected HAADF-STEM images reveal the presence of isolated $\mathrm{Pt}$ single sites (white circles), which are brighter compared to surrounding $\mathrm{Ce}$ due to their larger atomic number, and dispersed throughout the porous $\mathrm{CeO}_{2}$ support, as shown in Fig. $1 b^{5,32}$. Important additional information was obtained from X-ray absorption spectroscopy at the $\mathrm{Pt}$ $L_{3}$ edge, in experiments with $\mathrm{Pt}$ foils, $\mathrm{PtO}_{2}$ as a reference, and with the $\mathrm{Pt}_{1} / \mathrm{CeO}_{2}$ catalyst. The near-edge fine structure (XANES) provides insights into the valence state of Pt (Fig. 1c), while the extended X-ray adsorption fine structure part (EXAFS) provides information on the local bonding geometry ${ }^{33}$. The EXAFS data from the $\mathrm{Pt}_{1} / \mathrm{CeO}_{2}$ catalyst show only one peak from $\mathrm{Pt}-\mathrm{O}$ bonds around $1.5 \AA$, but no Pt-Pt bonds could be detected, as shown by comparison with the reference bulk $\mathrm{PtO}_{2}$ and $\mathrm{Pt}$ foil (Fig. 1d). Details of the EXAFS fitting results are listed in Supplementary Table 1. The combined evidence from Cs-corrected HAADFSTEM and EXAFS strongly support the conclusion that the Pt in the $\mathrm{Pt}_{1} / \mathrm{CeO}_{2}$ catalyst is largely present as isolated single atoms on $\mathrm{CeO}_{2}$ while no metallic particles or clusters are present in detectable amounts. In more detail, compared with the $\mathrm{PtO}_{2}$ reference, although there is not an obvious white line shift of $\mathrm{Pt}_{1} /$ $\mathrm{CeO}_{2}$ due to the low $\mathrm{Pt}$ concentration on the surface and detector limitation, the lower energy shoulder (Fig. 1) indicates that the Pt oxidation state in $\mathrm{Pt}_{1} / \mathrm{CeO}_{2}$ is lower than $+4^{34}$, in agreement with the ambient-pressure X-ray photoelectron spectroscopy (APXPS) results. These low oxidation state $\mathrm{Pt}$ species are critical to our proposed mechanism below, especially in the initial stage of the reaction.

Dehydrogenation of cyclohexane. As a reversible LOHC system, cyclohexane/benzene is ideal for the storage and transportation of hydrogen. Here we used the as-prepared $\mathrm{Pt}_{1} / \mathrm{CeO}_{2}$ single-site catalyst for the catalytic cyclohexane dehydrogenation reaction (Supplementary Fig. 2). The catalyst showed excellent activity compared to that of $\mathrm{Pt}$ nanoparticles on $\mathrm{CeO}_{2}\left(2.5 \mathrm{~nm} \mathrm{Pt} / \mathrm{CeO}_{2}\right.$ 

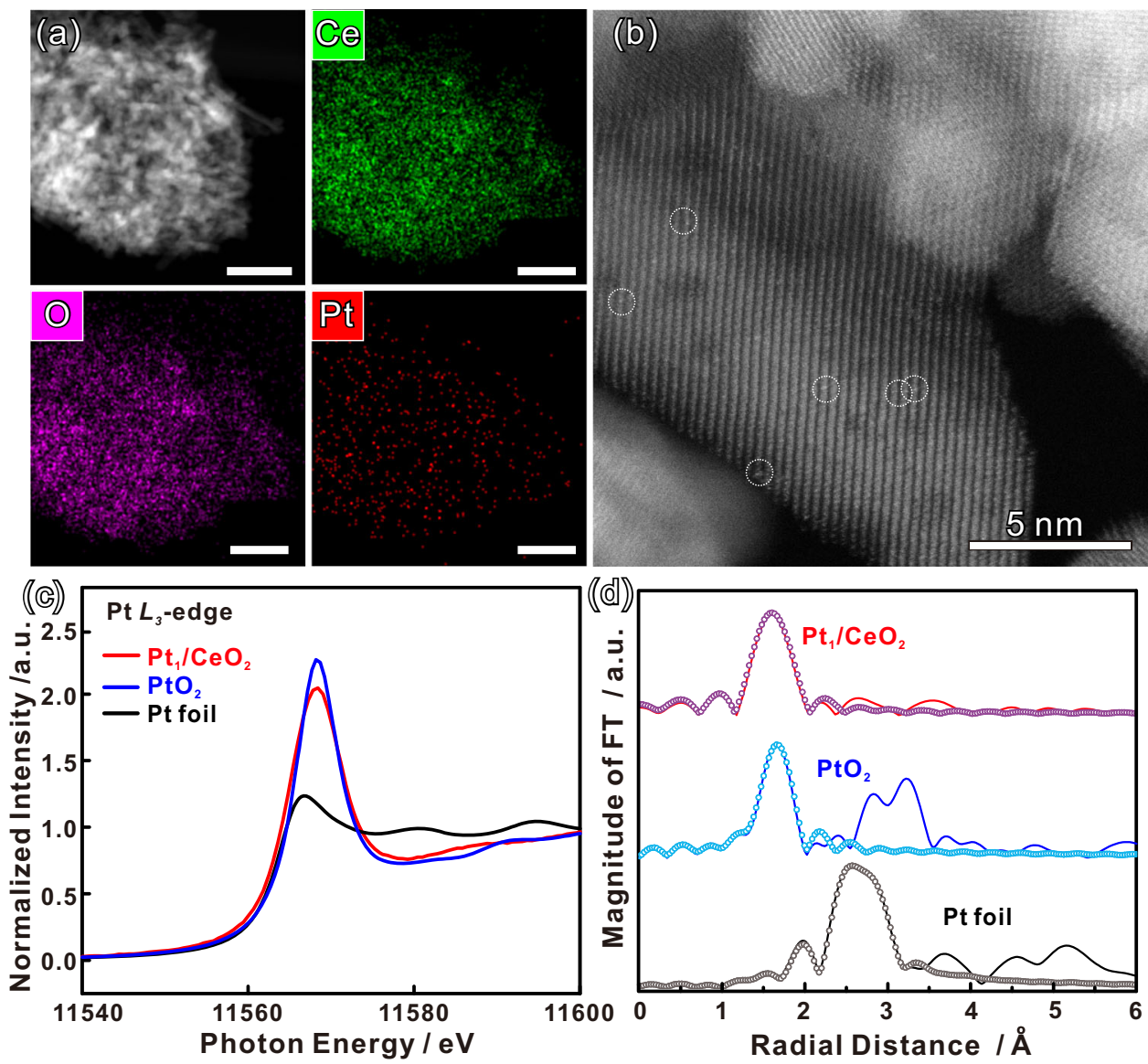

Fig. 1 Morphology and structural characterization of $\mathbf{P t} \mathbf{1} / \mathbf{C e O}_{\mathbf{2}}$ catalysts. a High-angle annular dark-field scanning transmission electron microscopy (HAADF-STEM) images and corresponding elemental map images of the $\mathrm{Pt}_{1} / \mathrm{CeO}_{2}$ catalyst (scale bars $=50$ nm). $\mathbf{b}$ Cs-corrected HAADF-STEM images of the $\mathrm{Pt}_{1} / \mathrm{CeO}_{2}$ catalyst. The brighter dots (circled) are from Pt single sites. c Normalized Pt $L_{3}$-edge XANES spectra, and (d) $k^{3}$-weighted Fourier transform EXAFS spectra ( $L_{3}$-edge) of $\mathrm{Pt}$ in $\mathrm{Pt}_{1} / \mathrm{CeO}_{2}, \mathrm{PtO}_{2}$, and bulk $\mathrm{Pt}$ foil at the $\mathrm{Pt} L_{3}$-edge. The circles are fit to the data.

and $7.0 \mathrm{~nm} \mathrm{Pt} / \mathrm{CeO}_{2}$ ), which were synthesized according to previous work (Supplementary Fig. 3) ${ }^{26}$. At temperatures below $100^{\circ} \mathrm{C}$ all the catalysts were inactive. When the temperature increased to $100{ }^{\circ} \mathrm{C}$ hydrogen was generated at measurable rates from the dehydrogenation of cyclohexane on the $\mathrm{Pt}_{1} / \mathrm{CeO}_{2}$ catalyst. With further increase in temperature, the TOF of hydrogen generation by cyclohexane dehydrogenation increased, reaching $32,477 \mathrm{~mol}_{\mathrm{H} 2} \mathrm{~mol}_{\mathrm{Pt}}{ }^{-1} \mathrm{~h}^{-1}\left(5.5 \mathrm{~g}_{\mathrm{H} 2} \mathrm{~g}_{\mathrm{Pt}}{ }^{-1} \mathrm{~min}^{-1}\right)$ at $350{ }^{\circ} \mathrm{C}$ (Fig. 2a), which is 309-fold higher than that of commercial Pt particles on aluminum oxide catalysts with $5 \%$ loading (Fig. 3). In contrast, no catalytic activity was detected with Pt nanoparticles of $2.5 \mathrm{~nm}$ and $7.0 \mathrm{~nm}$ size on $\mathrm{CeO}_{2}$ until the temperature increased to $400{ }^{\circ} \mathrm{C}$ (Fig. 3, Supplementary Table 2). To further assess the catalytic performance of $\mathrm{Pt}_{1} / \mathrm{CeO}_{2}$, we measured the TOF of hydrogen generation and conversion from cyclohexane at $350^{\circ} \mathrm{C}$ at different cyclohexane feed rates (Fig. 2b). At low feed rates $(0.01 \mathrm{~mL} / \mathrm{min})$, the conversion of cyclohexane reached $100 \%$, with a TOF around $10,900 \mathrm{~mol}_{\mathrm{H} 2} \mathrm{~mol}_{\mathrm{Pt}}{ }^{-1} \mathrm{~h}^{-1}\left(1.9 \mathrm{~g}_{\mathrm{H} 2}\right.$ $\left.\mathrm{g}_{\mathrm{Pt}^{-1}} \mathrm{~min}^{-1}\right)$. Alternatively, a higher TOF around 35,400 $\mathrm{mol}_{\mathrm{H} 2}$ $\mathrm{mol}_{\mathrm{Pt}}{ }^{-1} \mathrm{~h}^{-1}\left(6.0 \mathrm{~g}_{\mathrm{H} 2} \mathrm{~g}_{\mathrm{Pt}}{ }^{-1} \mathrm{~min}^{-1}\right)$ was achieved at feed rates of $0.1 \mathrm{~mL} / \mathrm{min}$. As shown in the literature, the equilibrium constant $\left(K_{\text {eq }}\right)$ of the dehydrogenation of cycloalkanes under an ambient pressure only depends on the reaction temperature ${ }^{35}$. And the equilibrium conversion for the dehydrogenation of cyclohexane and methylcyclohexane could reach $99 \%$ above $593 \mathrm{~K}$. In our study, the highest conversion at $350^{\circ} \mathrm{C}$ is around $30 \%$ (Fig. 2a), which is much lower than the equilibrium conversion. Therefore, the reaction TOF could reach values as high as $32,000-35,200 \mathrm{~mol}$ $\mathrm{H}_{2}$ per mol Pt per hour. These results illustrate the excellent catalytic activity of $\mathrm{Pt}_{1} / \mathrm{CeO}_{2}$ catalyst, and its potential for process scale-up. Moreover, the single-site $\mathrm{Pt}_{1} / \mathrm{CeO}_{2}$ catalyst exhibited remarkably high selectivity towards benzene production in the cyclohexane dehydrogenation reaction. At temperatures of $150^{\circ} \mathrm{C}$ and $200^{\circ} \mathrm{C}$, the major dehydrogenated product (more than $80 \%$ ) was benzene with $<20 \%$ of cyclohexene detected. When the temperature was above $250^{\circ} \mathrm{C}$, essentially only dehydrogenation product is benzene (Fig. 2c).

For practical applications, stability and recyclability are important parameters when evaluating long-term catalyst performance. After $72 \mathrm{~h}$ at $350{ }^{\circ} \mathrm{C}$ with $3 \mathrm{~mL} / \mathrm{h}$ cyclohexane feeding rate, the $\mathrm{Pt}_{1} / \mathrm{CeO}_{2}$ catalyst still maintains more than $90 \%$ of its original activity (Fig. 2d), the small decrease of activity results from the loss of some $\mathrm{Pt}$ species on $\mathrm{CeO}_{2}{ }^{26}$. The recyclability of $\mathrm{Pt}_{1} / \mathrm{CeO}_{2}$ catalyst was assessed by cyclic cyclohexane dehydrogenation experiments (Supplementary Fig. 4). The results indicate that there is no obvious activity decay during four cycles of cyclohexane dehydrogenation under different temperatures. EXAFS was also employed to confirm that the structure of $\mathrm{Pt}_{1} / \mathrm{CeO}_{2}$ remained stable after long reaction times and after repeated cycles of catalytic reaction. No apparent difference was found between used and freshly prepared $\mathrm{Pt}_{1} / \mathrm{CeO}_{2}$ catalysts, indicating that during reaction the fine structure of the $\mathrm{Pt}_{1} / \mathrm{CeO}_{2}$ remains unchanged (Supplementary Fig. 5). We attribute the high stability to the embedded nature of the $\mathrm{Pt}$ into the $\mathrm{CeO}_{2}$ surface layer, which is produced by 

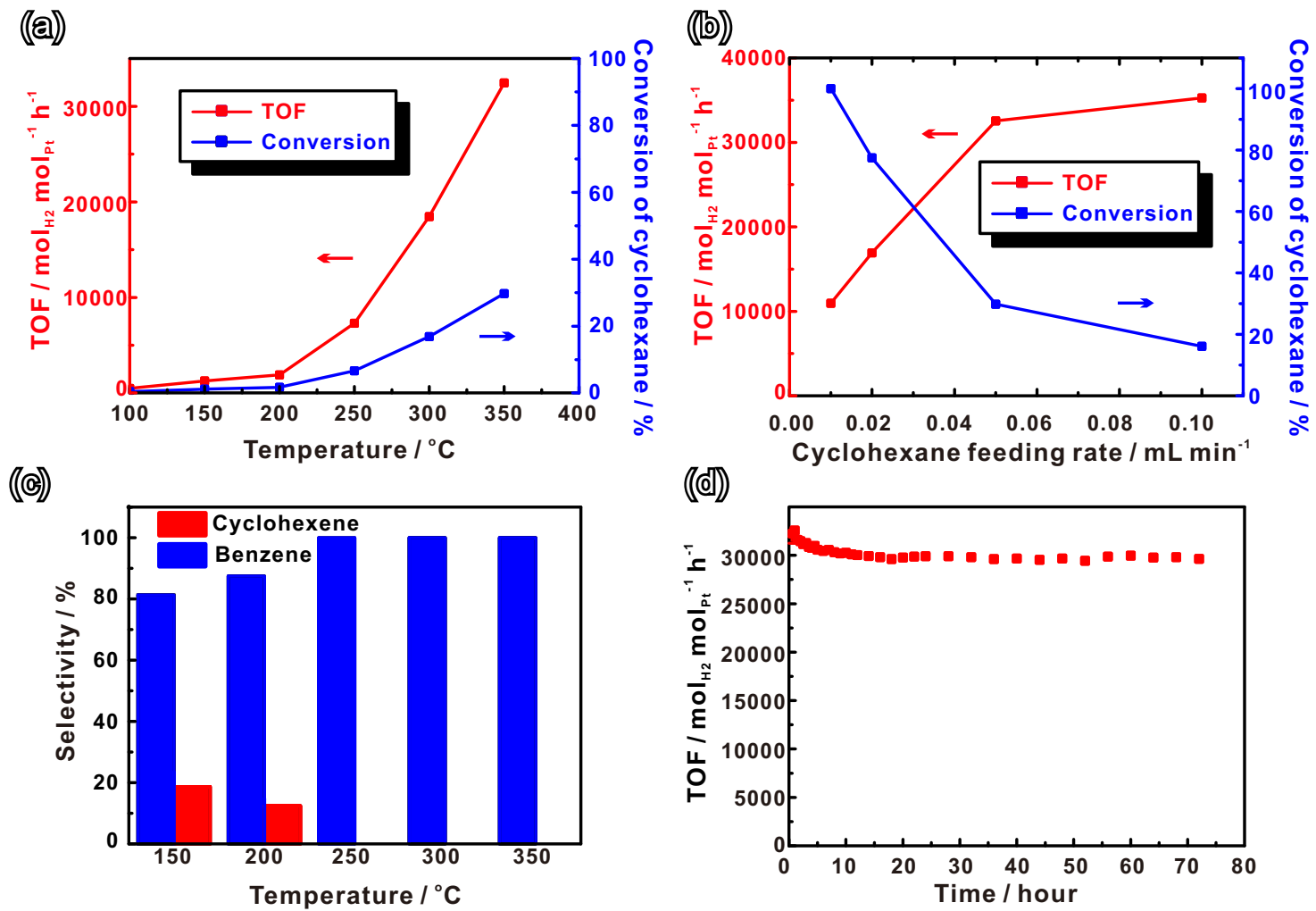

Fig. 2 Catalytic cyclohexane dehydrogenation performance of $\mathbf{P t}_{\mathbf{1}} / \mathbf{C e O}_{\mathbf{2}}$. a Turnover frequency (TOF) of hydrogen production per mol $\mathrm{Pt}$ of $\mathrm{Pt}_{1} / \mathrm{CeO} \mathrm{O}_{2}$ and conversion of cyclohexane at different temperatures. Reaction conditions: (b) turnover frequency (TOF) of hydrogen production per mol $\mathrm{Pt}$ of $\mathrm{Pt}_{1} / \mathrm{CeO}_{2}$ and conversion of cyclohexane at $350^{\circ} \mathrm{C}$ for different cyclohexane feeding rates. c Selectivity of cyclohexane dehydrogenation at different temperatures. d Turnover frequency (TOF) of hydrogen production per mol Pt of $\mathrm{Pt}_{1} / \mathrm{CeO}_{2}$ at $350^{\circ} \mathrm{C}$ during $72 \mathrm{~h}$ of reaction.

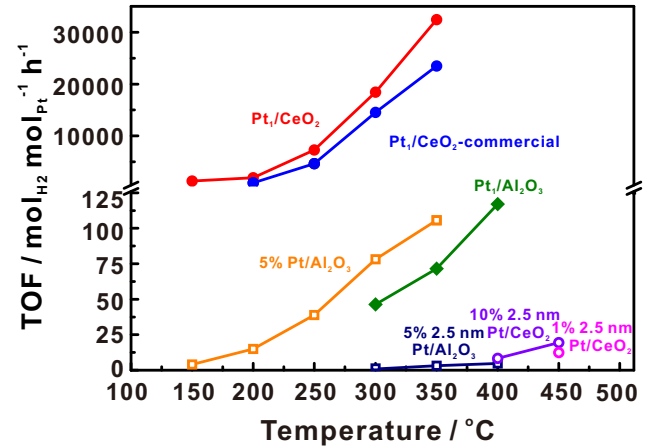

Fig. 3 Comparison $\mathrm{Pt}_{1} / \mathrm{CeO}_{2}$ catalytic performance with other catalysts. Turnover frequency (TOF) of hydrogen production per Pt site of different catalysts as a function of temperature. The circle symbols correspond to supports with cyclohexane adsorption ability while square symbols correspond to supports with no cyclohexane adsorption ability. Solid symbols denote single Pt site catalysts while hollow symbols denote Pt nanoparticle catalysts.

depositing it on a high surface area of $\mathrm{CeO}_{2}$ at relatively low $\mathrm{Pt}$ loading amounts ${ }^{36,37}$. In addition, the abundant $\mathrm{Ce}^{3+}$ species further increase the stability of $\mathrm{Pt}_{1} / \mathrm{CeO}_{2}$ catalysts ${ }^{38}$. However, increasing the temperature to $400{ }^{\circ} \mathrm{C}$ resulted in a decrease in reaction activity as a result of some $\mathrm{Pt}$ aggregation and carbon deposition, as revealed by EXAFS (Supplementary Figs. 5, 6).

Cyclohexane dehydrogenation on different catalysts. It has been reported that single-site catalysts have limitations for reactions involving large molecules due to the lack of surrounding ensemble sites to accommodate the molecule and its products. However, our results show that the single-site $\mathrm{Pt}_{1} / \mathrm{CeO}_{2}$ is 309 times more active than $\mathrm{Pt}$ particles supported on $\mathrm{CeO}_{2}$ or $\mathrm{Al}_{2} \mathrm{O}_{3}$, which ranks the highest among the reported catalysts (Supplementary Fig. 7) ${ }^{39}$. To understand this effect and the reaction mechanism, a comparison of the performance of Pt and its different ensemble size effects in different supports is needed. We tested the dehydrogenation reaction of cyclohexane on a series of catalysts such as different $\mathrm{Pt}$ nanoparticles of different sizes on $\mathrm{CeO}_{2}$, single-site $\mathrm{Pt}$ on $\mathrm{Al}_{2} \mathrm{O}_{3}$, and commercial $\mathrm{Pt}$ catalysts (5\% Pt/ $\mathrm{Al}_{2} \mathrm{O}_{3}$ ) (Fig. 3, Supplementary Fig. 8, and Supplementary Table 2). We found that on different $\mathrm{Pt}$ nanoparticles sizes $(2.5 \mathrm{~nm}$ and $7 \mathrm{~nm})$ loaded on $\mathrm{CeO}_{2}$, different pretreatments, and different Pt content, there was no hydrogen detected until the temperature was higher than $400{ }^{\circ} \mathrm{C}$. Moreover, for single-site $\mathrm{Pt}$ on $\mathrm{Al}_{2} \mathrm{O}_{3}\left(\mathrm{Pt}_{1} / \mathrm{Al}_{2} \mathrm{O}_{3}\right)$, which was synthesized following literature reports ${ }^{40}$, we found that although the $\mathrm{Pt}$ is also in single-atom form, its catalytic activity is much lower than that of $\mathrm{Pt}_{1} / \mathrm{CeO}_{2}$, indicating the aforementioned super-synergistic role played by the support in case of $\mathrm{Pt}_{1} / \mathrm{CeO}_{2}$.

To further elucidate the role of the support in the dehydrogenation reaction we used in situ DRIFTS to study cyclohexane adsorption and desorption ${ }^{41}$. The results showed that the as-prepared $\mathrm{Pt}_{1} / \mathrm{CeO}_{2}$ support exhibited much stronger adsorption of cyclohexane as compared to that of $\mathrm{Pt}_{1} / \mathrm{Al}_{2} \mathrm{O}_{3}$ (Supplementary Fig. 9). Due to the strong interaction between $\mathrm{CeO}_{2}$ and cyclohexane, after stopping the flow of cyclohexane and purging with pure $\mathrm{N}_{2}$ for $40 \mathrm{~min}$, there are still two peaks around $2930 \mathrm{~cm}^{-1}$ and $2852 \mathrm{~cm}^{-1}$ which are attributed to adsorbed cyclohexane, while for the $\mathrm{Al}_{2} \mathrm{O}_{3}$ support, these peaks disappeared after 15 min of $\mathrm{N}_{2}$ purging. Also, commercial $\mathrm{CeO}_{2}$ 

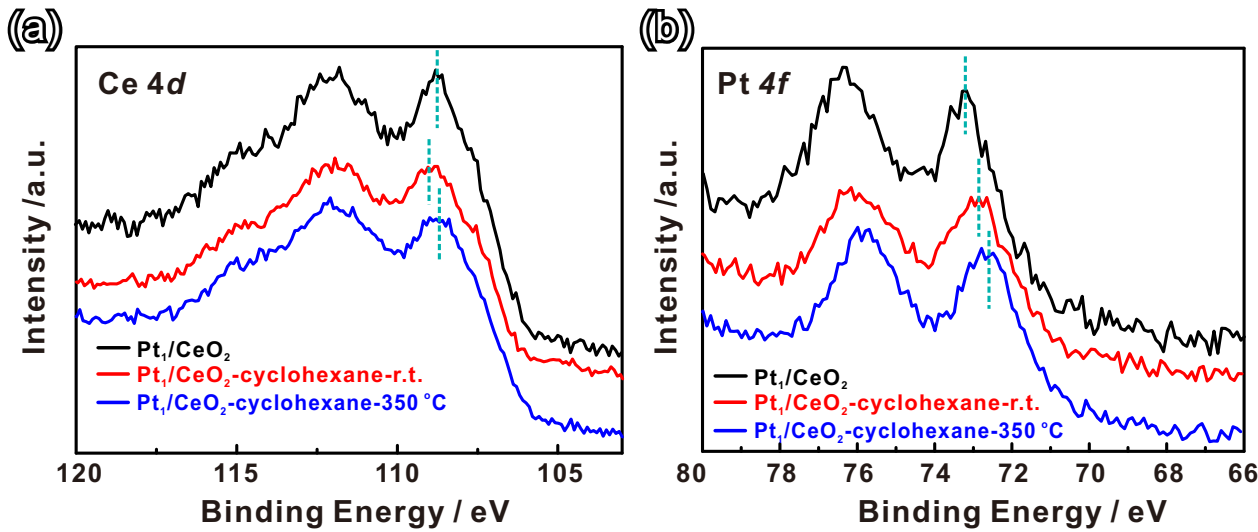

Fig. 4 In situ AP-XPS of $\mathbf{P t}_{\mathbf{1}} / \mathbf{C e O}_{\mathbf{2}}$ catalyst. a Ce $4 d$ and (b) Pt $4 f$ APXPS spectra of $\mathrm{Pt}_{1} / \mathrm{CeO}_{2}$ catalysts in different conditions. The black, red, and blue lines are $\mathrm{Pt}_{1} / \mathrm{CeO}_{2}$ in vacuum, in 0.1 Torr cyclohexane at room temperature and 0.1 Torr cyclohexane at reaction temperature of $350{ }^{\circ} \mathrm{C}$, respectively.

powders (Supplementary Fig. 10) were studied for cyclohexane adsorption using FTIR. We found that cyclohexane adsorption is very weak and all the cyclohexane desorbed during $10 \mathrm{~min}$ pure $\mathrm{N}_{2}$ purging. To confirm the cyclohexane adsorption site on $\mathrm{CeO}_{2}$, XPS was used to determine the Ce oxidation state in commercial $\mathrm{CeO}_{2}$ powders compared to that in the as-prepared $\mathrm{CeO}_{2}$ (Supplementary Fig. 11$)^{42}$. The Ce $3 d$ XPS spectra are very sensitive to its oxidation state, showing 10 peaks which are attributed to $\mathrm{Ce}^{3+}(881.0,883.4,899.3$ and $903.1 \mathrm{eV})$ and $\mathrm{Ce}^{4+}$ $(882.2,888.4,898.1,900.7,907.3$ and $916.7 \mathrm{eV})$, which were used to calculate the concentration of $\mathrm{Ce}^{3+}$ in $\mathrm{CeO}_{2}{ }^{32,43}$ The results show that the $\mathrm{O}$ vacancies $\left(\mathrm{V}_{\mathrm{O}}\right)$ in our $\mathrm{CeO}_{2}$ nanorods is higher than that in the commercial powders. To further verify that $V_{O}$ promote cyclohexane adsorption, we loaded $\mathrm{Pt}$ on commercial $\mathrm{CeO}_{2}$ by the same ascorbic acid (AA) assisted reduction method, which created some $\mathrm{V}_{\mathrm{O}}$ sites on $\mathrm{CeO}_{2}$ at the same time (Supplementary Table 2). The Pt $L_{3}$-edge EXAFS showed that similar to the $\mathrm{Pt}_{1} / \mathrm{CeO}_{2}$ catalyst, $\mathrm{Pt}$ on the commercial $\mathrm{CeO}_{2}$ particles was also a single site (Supplementary Fig. 5). The in situ DRIFTS (Supplementary Fig. 9) showed that the higher Vo concentration improved the cyclohexane adsorption ability, causing the $\mathrm{Pt}_{1} / \mathrm{CeO}_{2}$-commerical catalyst activity to be comparable to the activity of $\mathrm{Pt}_{1} / \mathrm{CeO}_{2}$ catalyst at lower temperature $\left(200^{\circ} \mathrm{C}\right)$.

Ambient-pressure X-ray photoelectron spectroscopy (AP-XPS). To identify the nature of the active site in $\mathrm{Pt}_{1} / \mathrm{CeO}_{2}$ during reaction, AP-XPS was employed to measure the valence state change of Pt and Ce during cyclohexane dehydrogenation. Fig $4 \mathrm{a}$ shows the $\mathrm{Ce} 4 d$ spectra of $\mathrm{Pt}_{1} / \mathrm{CeO}_{2}$ catalysts under different conditions ${ }^{44}$. We expect the lowest binding energy peak for $\mathrm{Ce}^{4+}$ at $109.3 \mathrm{eV}$ and for $\mathrm{Ce}^{3+}$ the stronger peak in this range appears at $108.0 \mathrm{eV}$ (with a much weaker peak at $105.4 \mathrm{eV}$ ) 45 . Based on the measured line shape, we can see a slightly increasing $\mathrm{Ce}^{3+}$ population with cyclohexane dosing and increased temperature, which was also confirmed by the NEXAFS results at the Ce $M_{4,5}$ edge after absorbing cyclohexane (Supplementary Fig. 12). Knowing from our FTIR results (Supplementary Fig. 9) that cyclohexane adsorption is driven by oxygen vacancies in our catalyst, after dosing 0.1 Torr of cyclohexane vapor, the binding energy of $\mathrm{Ce}^{4+} 4 d$ shifted to slightly higher energy, which we ascribe to surface polarization of $\mathrm{CeO}_{2}$ due to adsorbates (Fig. 4a). With further increase of the temperature to $350{ }^{\circ} \mathrm{C}$, which causes hydrogen generation from cyclohexane dehydrogenation, and driving off adsorbates, we notice that the $\mathrm{Ce}^{4+} 4 d$ peak shifts back to a lower energy ${ }^{46}$. The Pt $4 f$ XPS reveals lower binding energy peaks ranging from 73.2 to 72.9 to $72.6 \mathrm{eV}$, slightly above measured $\mathrm{PtO}$ peaks at $72.2 \mathrm{eV}\left(\mathrm{PtO}_{2} \text { appears at } 74.5 \mathrm{eV}\right)^{47}$. One possibility is that we may be seeing $\mathrm{Pt}^{3+}$ (reported $4 f$ binding energy of $\mathrm{Pt}^{3+}$ is $\left.73.3 \mathrm{eV}\right)^{48}$ due to chemical bonds formed with $\mathrm{Pt}^{2+}$ active sites (possibly remaining ligands on the as-prepared sample)-see our mechanism below. By contrast with Pt $L_{3}$ XANES, lower binding energy $4 f$ XPS is extremely surface sensitive and highlights a lower oxidation state dominance at the surface. After introducing 0.1 Torr cyclohexane, and then increasing the temperature, we see a slight reduction in $\mathrm{Pt} 4 f$ binding energy, which is evident as a slight reduction in valence charge due to the presence of adsorbates in our density functional theory (DFT) calculations. We saw no evidence for metallic Pt in any of these spectra (peak at $70.8 \mathrm{eV}$ ) which speaks to the stability of our catalyst at high operating temperatures.

Mechanism. The incorporation of the $\mathrm{Pt}$ atom into the ceria surface, by replacing a surface Ce atom, moves well beyond the strong metal-support interactions that might be expected for supported metal nanoparticles or clusters. Therefore, the traditional metal-support interaction and reaction models which were built based on the surface/interface of metal nanoparticles and support, can no longer precisely describe the interactions and reaction occurring in the local environment of a single metal atom $^{49,50}$. Our results, combining the characterization data reported above and DFT calculations of model catalyst reactions, show that the combination of (1) the incorporated Pt site, (2) a neighboring oxygen vacancy, and (3) the variable redox of $\mathrm{Ce}$ provide the necessary flexibility to catalyze multiple reactions. Specifically, the combination of these three components in the single-site $\mathrm{Pt}_{1} / \mathrm{CeO}_{2}$ catalyst enables: adsorption, activation, and reaction of reactant (cyclohexane); $\mathrm{H}$ species spillover; and $\mathrm{H}_{2}$ reformation. We refer to this as a super-synergistic effect, by contrast with synergistic catalysis ${ }^{51}$, in which two distinct catalysts can enhance reactions between two different reactants.

The in situ FTIR and AP-XPS results indicate that the ceria support, especially the abundance of oxygen vacancies, plays a significant role during cyclohexane adsorption and dehydrogenation. In a perfect crystal of $\mathrm{CeO}_{2}$, the formal oxidation state of $\mathrm{Ce}$ is $\mathrm{Ce}^{4+}$ with no oxygen vacancies and $\mathrm{Pt}$ substitution for $\mathrm{Ce}$ would nominally place it in the same $\mathrm{Pt}^{4+}$ oxidation state, but, in combination with an oxygen vacancy ${ }^{52,53}$, our DFT calculations show that the Pt $5 d$ unoccupied orbitals lie just lower in energy than the Ce $4 f$ orbitals, and so the two excess valence electrons released by the $\mathrm{O}$ vacancy reduce $\mathrm{Pt}^{4+}$ to $\mathrm{Pt}^{2+}$, which adopts the signature of the planar $\mathrm{PtO}_{4}$ coordination of $\mathrm{Pt}^{2+}$ by breaking bonds with two ceria $\mathrm{O}$ atoms (Supplementary Fig. 20). We propose that the super-synergistic coupling between the 
single-atom Pt and the ceria support with oxygen vacancy is driven by redox coupling (or disproportionation) between both the metal ions:

$$
\mathrm{Pt}^{2+}+\mathrm{Ce}^{4+} \rightarrow \mathrm{Pt}^{3+}+\mathrm{Ce}^{3+},
$$

which is vital for forming chemical bonds between formally radical intermediates and the single-site Pt. We propose two dominant reactions for cyclohexane dehydrogenation:

(1) Hydrogen abstraction and $\mathrm{Pt}-\mathrm{C}$ bond (denoted as $\mathrm{Pt}-\mathrm{C}$ bond) formation:

$$
\left(\mathrm{C}_{6} \mathrm{H}_{2 n}\right)^{*}+\mathrm{Pt}^{2+}+\mathrm{O}^{2-}+2 \mathrm{Ce}^{4+} \rightarrow \mathrm{Pt}^{3+}-\left(\mathrm{C}_{6} \mathrm{H}_{2 n-1}\right)+\mathrm{OH}^{-}+2 \mathrm{Ce}^{3+} \text {, }
$$

where $n=6,5,4$. Removal of a neutral $\mathrm{H}$ atom from the organic group would nominally produce two radicals. The (neutral) $\mathrm{H}$ atom sheds its electron to form $\mathrm{Ce}^{3+}$ and joins the oxide dianion to produce a hydroxide ion $\left(\mathrm{OH}^{-}\right)$(Supplementary Figs. 15, 16). The $5 d^{8}$ electronic configuration of $\mathrm{Pt}^{2+}$ cannot bind with the organic radical, so it sheds an electron to form another $\mathrm{Ce}^{3+}$ and accepts the radical's electron into a now half-filled $5 d$ orbital, forming a strong bond with the $\mathrm{C}$ atom of the adsorbate.

(2) $\mathrm{H}$ abstraction and $\mathrm{Pt}<\mathrm{C}=\mathrm{C}$ bond (denoted as $\mathrm{Pt}<\mathrm{C}=\mathrm{C}$ bond) formation:

$$
\begin{aligned}
\mathrm{Pt}^{3+} & -\left(\mathrm{C}_{6} \mathrm{H}_{2 n-1}\right)+\mathrm{Ce}^{3+}+\mathrm{O}^{2-}+2 \mathrm{Ce}^{4+} \rightarrow \mathrm{Pt}^{2+}<\mathrm{C}_{6} \mathrm{H}_{2 n-2} \\
& +\mathrm{Ce}^{4+}+\mathrm{OH}^{-}+2 \mathrm{Ce}^{3+}
\end{aligned}
$$

where $n=6,5,4$ again. In this case, the Pt reverts to its original $\mathrm{Pt}^{2+}$ oxidation state and bonds with the $\pi$ electrons of a $\mathrm{C}=\mathrm{C}$ double bond, effectively bonding with both the carbon atoms. In the process, the $\mathrm{Pt}$ atoms rotates its bonding plane to meet the $\mathrm{C}=\mathrm{C}$ double bond by breaking two $\mathrm{O}$ bonds and forming one new $\mathrm{O}$ bond (Supplementary Fig. 17). The high cation coordination of the cubic ceria crystal provides this flexibility for the Pt to adjust its bonding environment and make these two very different bonds to accommodate saturated and unsaturated hydrocarbons both present in dehydrogenation products.

We also propose an analogous super-synergy exists for the dehydrogenation of the catalyst surface, to dissociate $\mathrm{H}_{2}$ or recombine protons and electrons into $\mathrm{H}_{2}$ molecules via a $\mathrm{Pt}-\mathrm{H}$ bound intermediate (Supplementary Fig. 18):

$$
\begin{gathered}
\left(\mathrm{H}_{2}\right)^{*}+\mathrm{Pt}^{2+}+2 \mathrm{Ce}^{4+} \rightarrow \mathrm{Pt}^{3+}-\mathrm{H}+\mathrm{OH}^{-}+2 \mathrm{Ce}^{3+}, \\
2 \mathrm{OH}^{-}+\mathrm{Pt}^{2+}+2 \mathrm{Ce}^{3+} \rightarrow \mathrm{Pt}^{3+}-\mathrm{H}+\mathrm{OH}^{-}+\mathrm{O}^{2-}+2 \mathrm{Ce}^{3+} .
\end{gathered}
$$

To summarize this analysis derived from DFT calculations, the super-synergy results from: the incorporation of a $\mathrm{Pt}$ atom by substitution at a surface Ce site; a neighboring oxygen vacancy; and the variable redox of Ce. The major features of super-synergy are as follows: (1) The exchange of electrons between the active Pt site and the ceria support permits facile switching of the function of the $\mathrm{Pt}$ atom in binding directly to a single $\mathrm{C}$ atom of a radical adsorbate versus binding to a pair of atoms in a $\mathrm{C}=\mathrm{C}$ double bond of a non-radical adsorbate; (2) The disproportionation between $\mathrm{Pt}$ and $\mathrm{Ce}$ oxidation states facilitates $\mathrm{H}$ abstraction or addition via spillover (with similar duality for dissociation or recombination of $\mathrm{H}_{2}$; and (3) the reducible ceria support acts as a reservoir for abstracted hydrogen to permit serial dehydrogenation of adsorbed aromatics followed by reformation and release of $\mathrm{H}_{2}$.

Now, we can sequentially combine these reactions (Fig. 5) to reveal how $\mathrm{Pt}_{1} / \mathrm{CeO}_{2}$ favorably dehydrogenates cyclohexane to produce benzene, without the need for multiple catalytic sites due to the super-synergy just described. Both cyclohexane and benzene exhibit reasonable physisorption energies $(-18.8$ and $-15.9 \mathrm{kcal} / \mathrm{mol}$, respectively, from DFT calculations) due to the presence of oxygen vacancies and validated above using DRIFTS and X-ray spectroscopy. This is welcome, as our previous study

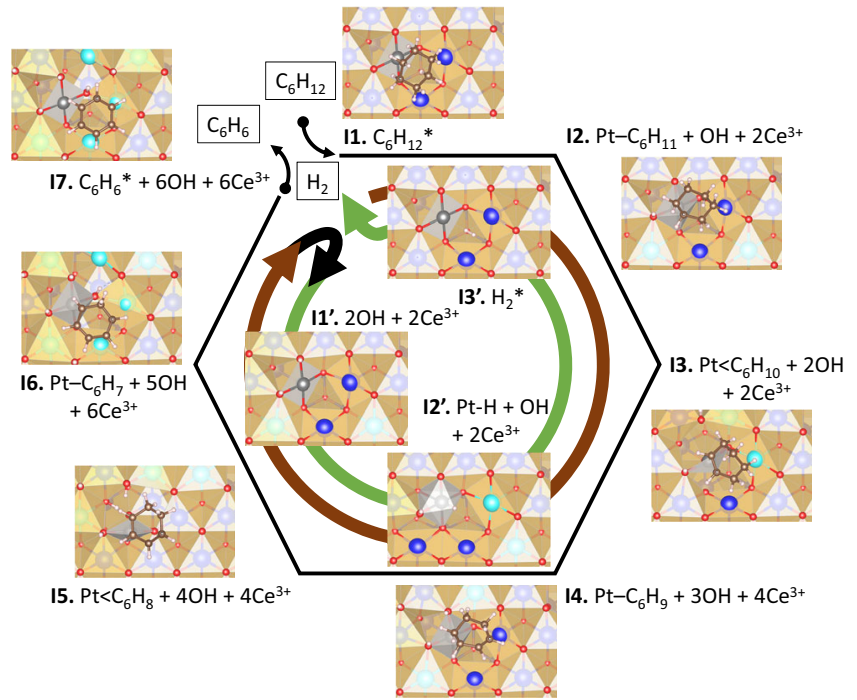

Fig. 5 Cyclohexane dehydrogenation pathway on $\mathrm{Pt}_{\mathbf{1}} / \mathrm{CeO}_{2}$ catalyst. Proposed cyclohexane dehydrogenation pathway (brown arrow) on $\mathrm{Pt}_{1} /$ $\mathrm{CeO}_{2}$ at an $\mathrm{O}$ vacancy $\left(\mathrm{V}_{\mathrm{O}}\right)$ involving $\mathrm{H}$ abstraction to the catalyst surface (as $\mathrm{OH}^{-}$) with associated formation of small polarons $\left(\mathrm{Ce}^{3+}\right.$ ) followed by recombination and release of $\mathrm{H}_{2}$ (green arrow). Reaction intermediates are labeled as I1-I7 (dehydrogenation) and $\mathbf{~ 1 1 ' - 1 3 '}\left(\mathrm{H}_{2}\right.$ release), with relative energies provided in Supplementary Fig. 19 of the Supporting Information. Structural snapshots are provided for each intermediate. $\mathrm{Ce}^{4+}$ : light blue (sub-surface) and dark blue (surface); $\mathrm{Ce}^{3+}$ : turquoise; Pt: gray; O: red; $\mathrm{H}$ : white.

showed that single metal sites had poor adsorption of molecules such as $\mathrm{CO}^{26}$. However, the mechanism here is clearly dominated by the successive exothermic formation of strongly bound surface hydroxy anions (Supplementary Fig. 19). In principle, in the absence of kinetic data (i.e., activation energies), the thermodynamic driving force is present to advance the dehydrogenation. Usually, $\mathrm{H}_{2}$ reformation from a metal oxide surface is the ratedetermining step for hydrocarbon dehydrogenation and requires high reaction temperatures 54,55 , fortunately, due to the presence of the single-atom $\mathrm{Pt}$ site, the energy cost for $\mathrm{H}_{2}$ reformation and desorption is reduced significantly (Supplementary Fig. 19). At functional temperatures, the saturated local environment around each $\mathrm{Pt}$ single-site can be purged by releasing $\mathrm{H}_{2}$ gas and the next cyclohexane molecule can be processed. Similarly, for hydrogenation of benzene, the favorable dissociation of physisorbed $\mathrm{H}_{2}$ will enrich the vicinity of the $\mathrm{Pt}$ single-site with available hydrogen that can then begin to resaturate benzene. Now it is the uphill process of cyclohexane reformation that requires high temperatures.

As shown in Supplementary Fig. 9, the commercial $\mathrm{CeO}_{2}$, which has a low oxygen vacancy concentration, has very poor capacity for cyclohexane adsorption. With the ascorbic acid treatment, Pt single sites are formed together with $\mathrm{O}$ vacancies in the support, which promotes the adsorption of cyclohexane. The calculated adsorption energies of cyclohexane on $\mathrm{CeO}_{2}$ slab, $\mathrm{CeO}_{2}$ slab with one oxygen vacancy, $\mathrm{Pt}_{1} / \mathrm{CeO}_{2}$ slab and $\mathrm{Pt}_{1} / \mathrm{CeO}_{2}$ slab with one oxygen vacancy are $-10.5,-14.8,-11.8,-18.8 \mathrm{kcal} / \mathrm{mol}$, respectively. However, the super-synergy between $\mathrm{Pt}$ and $\mathrm{Ce}$ cations is also vital. This explains why on the inert support of $\mathrm{Al}_{2} \mathrm{O}_{3}$, there is no cyclohexane adsorption (no vacancies), and dehydrogenation of cyclohexane at low temperature does not occur $\left(\mathrm{Al}^{3+}\right.$ cannot easily change oxidation state). In contrast, the Pt nanoparticles on $\mathrm{Al}_{2} \mathrm{O}_{3}$ show detectable dehydrogenation reaction of cyclohexane, due to typical metal surface catalysis ${ }^{48}$. These results clearly outline stark differences between the dehydrogenation mechanisms of single $\mathrm{Pt}$ 
sites and Pt nanoparticles. At last, compared with cyclohexane, intermediates such as cyclohexene and cyclohexadiene have been reported to be more active and easier to dehydrogenate to

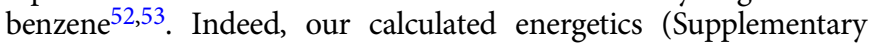
Fig. 19) indicate that these intermediate cyclic alkenes (I3 and I5 in Fig. 5) are increasingly stable on the path towards generating the triene, benzene. The only uphill process is the generation of the penultimate intermediate, $\mathrm{C}_{6} \mathrm{H}_{7}$. However, given that all species are strongly bound to the surface, this helps explain the observed high selectivity (100\%) towards benzene, at high temperature (Fig. 2b).

Benzene hydrogenation. An ideal LOHC system would feature both the hydrogen-rich and hydrogen-deficient organic compounds as liquids. And the usage of a proper catalytic system would allow for the efficient release of hydrogen by promoting the dehydrogenation reaction, and recovery of the hydrogen depleted by dehydrogenation. Hence, hydrogenation of benzene by the same single $\mathrm{Pt}_{1} / \mathrm{CeO}_{2}$ catalyst was investigated. As shown in the literature, high temperature and low pressure favor the dehydrogenation, and, reversibly, high $\mathrm{H}_{2}$ pressure and relatively low temperature favor the rehydrogenation. Therefore, in our study, which is different from these dehydrogenation reactions, dehydrogenation was carried out in gas-phase fixed-bed reactor with ambient pressure at a temperature of $350{ }^{\circ} \mathrm{C}$, the hydrogenation reactions were carried out in a liquid-phase batch reactor with a low reaction temperature $\left(60-120^{\circ} \mathrm{C}\right)$ and high $\mathrm{H}_{2}$ pressure (3.40-27.22 atm). Interestingly, for the benzene hydrogenation reaction, the single-site $\mathrm{Pt}_{1} / \mathrm{CeO}_{2}$ catalyst showed excellent catalytic activity, much higher than that of Pt nanoparticle catalysts $\left(2.5 \mathrm{~nm} \mathrm{Pt} / \mathrm{CeO}_{2}\right.$ and $7 \mathrm{~nm} \mathrm{Pt} / \mathrm{CeO}_{2}$ ) (Fig. 6) ${ }^{56}$. We further tested $\mathrm{Pt}_{1} / \mathrm{CeO}_{2}$ catalytic properties under different reaction conditions (Supplementary Fig. 13). Under $27.22 \mathrm{~atm} \mathrm{H}_{2}$ and at $120^{\circ} \mathrm{C}$, with a molar ratio of $\mathrm{H}_{2}$ to benzene of 5 to 1 in the batch reactor, we found that $50 \%$ of the benzene could be rehydrogenated. Our experiments indicate that conversion of benzene increases with reaction temperature and hydrogen pressure, as well as with the ratio of $\mathrm{H}_{2}$ to benzene. Therefore, a higher conversion (>99\%) of rehydrogenation of benzene or toluene could be anticipated by further optimizing the reaction conditions (especially with high $\mathrm{H}_{2}$ pressure).

Reversible dehydrogenation/hydrogenation of methylcyclohexane/toluene. In the practical application of liquid cyclohexane as carrier to store and transport hydrogen, the dehydrogenation product, benzene, is classified as a carcinogen. By comparison,

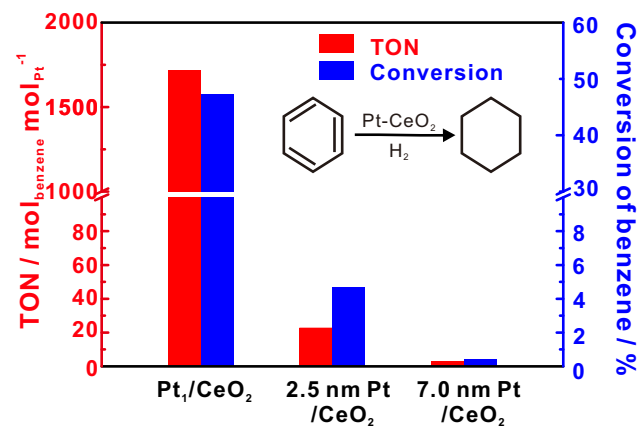

Fig. 6 Catalytic benzene hydrogenation performance of on $\mathrm{Pt}_{1} / \mathrm{CeO}_{2}$ and related catalyst. Catalytic benzene hydrogenation on $\mathrm{Pt}-\mathrm{CeO}_{2}$ catalysts $\left(\mathrm{Pt}_{1} / \mathrm{CeO}_{2}, 2.5 \mathrm{~nm} \mathrm{Pt} / \mathrm{CeO}_{2}\right.$, and $\left.7 \mathrm{~nm} \mathrm{Pt} / \mathrm{CeO}_{2}\right)$. Turnover number (TON) of benzene conversion per $\mathrm{Pt}$ site for $8 \mathrm{~h}$ and conversion of benzene on different Pt- $\mathrm{CeO}_{2}$ catalysts. Reaction conditions: $40 \mathrm{mg}$ catalysts dispersed in $3 \mathrm{~mL} n$-heptane; addition of $100 \mu \mathrm{L}$ of benzene in $27.22 \mathrm{~atm}$ of hydrogen gas at $120^{\circ} \mathrm{C}$ and stirred for $8 \mathrm{~h}$. toluene, the dehydrogenation product of methylcyclohexane, although with a similar structure as benzene, has much lower toxicity. Strikingly, we found that, during the methylcyclohexane dehydrogenation, the $\mathrm{Pt}_{1} / \mathrm{CeO}_{2}$ single-site catalyst also exhibited outstanding catalytic activity for dehydrogenation. Under the reaction conditions $\left(350{ }^{\circ} \mathrm{C}\right)$, the TOF of hydrogen production was about $29,300 \mathrm{~mol}_{\mathrm{H} 2} \mathrm{~mol}_{\mathrm{Pt}}{ }^{-1} \mathrm{~h}^{-1}$ without any other byproducts. As for toluene hydrogenation, $800 \mathrm{~mol}_{\text {toluene }} \mathrm{mol}_{\mathrm{Pt}}{ }^{-1}$ was achieved under relatively mild reaction conditions (Fig. 7 and Supplementary Fig. 14). That means this efficient single-site $\mathrm{Pt}_{1} /$ $\mathrm{CeO}_{2}$ catalyst can be also applied in methylcyclohexane/toluene reversible hydrogen storage and transportation 57,58 .

In summary, we demonstrated the advantages of ensemble reaction sites formed by a single $\mathrm{Pt}$ atom and surrounding oxygen vacancies, $\mathrm{Pt}_{1} / \mathrm{CeO}_{2}$, for the dehydrogenation and rehydrogenation of large molecule reactants such as cyclohexane and methylcyclohexane. Compared to nanoparticles catalysts $(2.5 \mathrm{~nm}$ and $7.0 \mathrm{~nm}$ size Pt particles on $\mathrm{CeO}_{2}$ and commercial $5 \% \mathrm{Pt}_{2} / \mathrm{Al}_{2} \mathrm{O}_{3}$ ), the $\mathrm{Pt}_{1} /$ $\mathrm{CeO}_{2}$ catalyst exhibits greatly enhanced reaction rates of cyclohexane dehydrogenation, 309 times higher than that of conventional supported Pt nanoparticles. At the same time, the single-site $\mathrm{Pt}_{1} /$ $\mathrm{CeO}_{2}$ catalyst also has significantly higher activity in the reaction of benzene hydrogenation. Moreover, this single-site catalyst was highly efficient in the dehydrogenation and hydrogenation of other aromatics, such as methylcyclohexane/toluene system for hydrogen generation and storage.

The combined results of in situ DRIFTS, APXPS, and EXAFS presented here demonstrate that the electronic properties and catalytic activity of our single-site $\mathrm{Pt}_{1} / \mathrm{CeO}_{2}$ catalyst can be precisely assigned to specific interactions between Pt atoms and neighboring surface atoms of the substrate. The mechanism predicted by our DFT studies is described as super synergistic. Unlike Pt nanoparticle catalysts, our single-site $\mathrm{Pt}_{1} / \mathrm{CeO}_{2}$ catalyst facilitates strong adsorption of large reactants due to surface oxygen vacancies that provide direct access to binding to the $\mathrm{Pt}$ site. Redox coupling between $\mathrm{Pt}$ and $\mathrm{Ce}$ ions and switchable $\mathrm{O}$ coordination environments permit alternating binding to radical and unsaturated by-products of $\mathrm{H}$ abstraction/addition. Spillover of $\mathrm{H}$ atoms to the $\mathrm{CeO}_{2}$ (111) surface is reversible via the Pt site and the same redox switching mechanism. And so, this combination can facilitate multiple reactions at a single site. Our results expand the application range of single-site catalyst to include large molecular reactants. They also highlight the versatility of a single-site catalyst for driving multiple reactions, paving the way for further rational design of highly efficient catalysts for sustainable energy generation and storage.

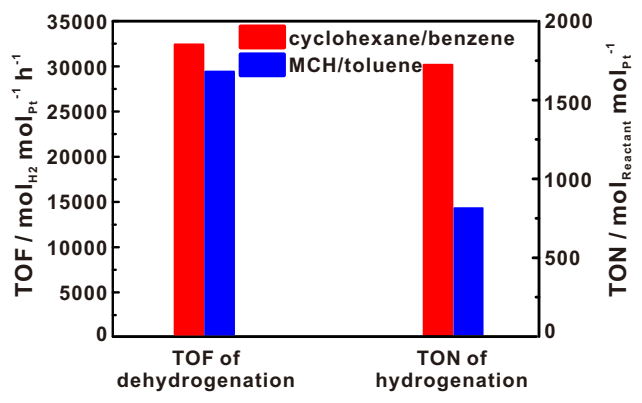

Fig. 7 Comparisons of dehydrogenation and hydrogenation efficiency of different molecules. Dehydrogenation reaction conditions: $100 \mathrm{mg}$ catalyst mixed with $500 \mathrm{mg}$ sand; Gas flow: $\mathrm{N}_{2} 30 \mathrm{ml} / \mathrm{min}$; Methylcyclohexane feeding rate: $3 \mathrm{~mL} / \mathrm{h}$; temperature: $350^{\circ} \mathrm{C}$. Hydrogenation reaction conditions: $40 \mathrm{mg}$ catalyst dispersed in $3 \mathrm{~mL} n$-heptane; added $100 \mu \mathrm{L}$ toluene under $27.22 \mathrm{~atm}$ hydrogen at $120^{\circ} \mathrm{C}$ and stirred for $12 \mathrm{~h}$. 


\section{Methods}

Catalyst preparation. The isolated single $\mathrm{Pt}$ sites on $\mathrm{CeO}_{2}\left(\mathrm{Pt}_{1} / \mathrm{CeO}_{2}\right)$ were fabricated by a modified ascorbic acid (AA)-assisted reduction method. The porous $\mathrm{CeO}_{2}$ nanorods were first synthesized according to previous reports. $500 \mathrm{mg}$ asprepared $\mathrm{CeO}_{2}$ was dispersed in $175 \mathrm{~mL}$ distilled water, $1 \mathrm{mmol}(0.176 \mathrm{~g}) \mathrm{AA}$ was added, and the solution was stirred at room temperature for $3 \mathrm{~h}$. The collected products were washed with distilled water several times and dried in vacuum, denoted as $\mathrm{CeO}_{2}$-AA. Second, $140 \mathrm{mg} \mathrm{CeO}-\mathrm{AA}$ powder was dispersed in $55 \mathrm{~mL}$ distilled water and $0.4 \mathrm{~mL}(10 \mathrm{mg} / \mathrm{mL}) \mathrm{H}_{2} \mathrm{PtCl}_{6}$ solution was added to it. After stirring for $3 \mathrm{~h}$ at room temperature, the products were collected and washed with water. After drying in vacuum, the products were calcined at $300^{\circ} \mathrm{C}$ for $1 \mathrm{~h}$ in air to remove excess AA.

Dehydrogenation of cyclohexane. The catalytic activity of catalysts toward hydrogen production from cyclohexane was performed in a continuous flow reactor. In a typical catalytic measurement, the $100 \mathrm{mg}$ catalyst was placed in a U-shape fixed-bed flow reactor after mixing with $500 \mathrm{mg}$ white quartz (50-70 mesh particle size). The feed of $30 \mathrm{~mL} / \mathrm{min} \mathrm{N}_{2}$ regulated by a mass flow controller to be at $1 \mathrm{~atm}$ and feed of $3 \mathrm{~mL} / \mathrm{h}$ cyclohexane controlled by an injection pump were mixed together and directed towards the catalysts. The temperature of bed was monitored by a K-type thermocouple controlled by a PID 679 controller. The products were analyzed online by HP 5890 GC (hayesep D column and hayesep Q column) equipped with TCD and FID detector. Besides, the liquid products were also collected and measured by NMR (AV-700).

The turnover frequency (TOF) is calculated using the following equation:

$$
\mathrm{TOF}=\frac{\text { Hydrogen Production }}{\text { Number of active Pt Sites } \times \text { time }}
$$

Hydrogenation of benzene. The catalytic activity of benzene hydrogenation was performed in BioTage Endeavor parallel pressure reactor. In a typical catalytic measurement, $40 \mathrm{mg}$ catalyst was dispersed in $3 \mathrm{~mL} n$-heptane, then $100 \mu \mathrm{L}$ benzene was added to the solution. After stirring the reaction mixture at $120^{\circ} \mathrm{C}$ for $8 \mathrm{~h}$ under $27.22 \mathrm{~atm}$ hydrogen, the product was analyzed by NMR (AV-700).

The conversion and turnover number (TON) are calculated using the following equations:

$$
\begin{gathered}
\text { Conversion }=\frac{\text { Output of Cyclohexane }}{\text { Input of Benzene }} \times 100 \% \\
\text { TON }=\frac{\text { Cyclohexane Production }}{\text { Number of active Pt Sites } \times \text { time }}
\end{gathered}
$$

Received: 6 December 2021; Accepted: 20 January 2022;

Published online: 01 March 2022

\section{References}

1. Munnik, P. et al. Recent developments in the synthesis of supported catalysts. Chem. Rev. 115, 6687-6718 (2015).

2. Tauster, S. J. Strong metal-support interactions. Acc. Chem. Res. 20, 389-394 (1987).

3. Xie, C. et al. Surface and interface control in nanoparticle catalysis. Chem. Rev. 120, 1184-1249 (2019).

4. Conner, W. C. Jr. et al. Spillover in heterogeneous catalysis. Chem. Rev. 95, 759-788 (1995).

5. Nie, L. et al. Activation of surface lattice oxygen in single-atom $\mathrm{Pt} / \mathrm{CeO}_{2}$ for low-temperature CO oxidation. Science 358, 1419-1423 (2017).

6. Nielsen, M. et al. Low-temperature aqueous-phase methanol dehydrogenation to hydrogen and carbon dioxide. Nature 495, 85-89 (2013).

7. Yao, S. et al. Atomic-layered Au clusters on $\alpha-\mathrm{MoC}$ as catalysts for the lowtemperature water-gas shift reaction. Science 357, 389-393 (2017).

8. Qiao, B. et al. Single-atom catalysis of $\mathrm{CO}$ oxidation using $\mathrm{Pt}_{1} / \mathrm{FeO}_{\mathrm{x}}$. Nat. Chem. 3, 634-641 (2011).

9. Yang, X. F. et al. Single-atom catalysts: a new frontier in heterogeneous catalysis. Acc. Chem. Res. 46, 1740-1748 (2013).

10. Chen, Y. et al. Single-atom catalysts: synthetic strategies and electrochemical applications. Joule 2, 1242-1264 (2018).

11. Wang, A. et al. Heterogeneous single-atom catalysis. Nat. Rev. Chem. 2, 65-81 (2018)

12. Jones, J. et al. Thermally stable single-atom platinum-on-ceria catalysts via atom trapping. Science 353, 150-154 (2016).

13. Shan, J. et al. Mild oxidation of methane to methanol or acetic acid on supported isolated rhodium catalysts. Nature 551, 605-608 (2017).

14. Liu, P. et al. Photochemical route for synthesizing atomically dispersed palladium catalysts. Science 352, 797-800 (2016).
15. Jeong, H. et al. Highly durable metal ensemble catalysts with full dispersion for automotive applications beyond single-atom catalysts. Nat. Catal. 3, 368-375 (2020).

16. Jeong, $\mathrm{H}$. et al. Fully dispersed Rh ensemble catalyst to enhance lowtemperature activity. J. Am. Chem. Soc. 140, 9558-9565 (2018).

17. $\mathrm{Yu}, \mathrm{K}$. et al. Asymmetric oxygen vacancies: the intrinsic redox active sites in metal oxide catalysts. Adv. Sci. 7, 1901970 (2020).

18. $\mathrm{Li}, \mathrm{T}$. et al. Maximizing the number of interfacial sites in single-atom catalysts for the highly selective, solvent-free oxidation of primary alcohols. Angew. Chem. Int. Ed. 57, 7795-7799 (2018).

19. Wang, L. et al. Single-site catalyst promoters accelerate metal-catalyzed nitroarene hydrogenation. Nat. Comm. 9, 1-8 (2018).

20. Steele, B. C. H. et al. Materials for fuel-cell technologies. Nature 414, 345 (2001).

21. Tromp, T. K. et al. Potential environmental impact of a hydrogen economy on the stratosphere. Science 300, 1740-1742 (2003).

22. Schultz, M. G. et al. Air pollution and climate-forcing impacts of a global hydrogen economy. Science 302, 624-627 (2003).

23. Tseng, P. et al. A hydrogen economy: opportunities and challenges. Energy 30, 2703-2720 (2005).

24. Teichmann, D. et al. A future energy supply based on Liquid Organic Hydrogen Carriers (LOHC). Energy Environ. Sci. 4, 2767-2773 (2011).

25. Markiewicz, M. et al. Environmental and health impact assessment of Liquid Organic Hydrogen Carrier (LOHC) systems-challenges and preliminary results. Energy Environ. Sci. 8, 1035-1045 (2015).

26. Chen, L. N. et al. Efficient hydrogen production from methanol using a singlesite $\mathrm{Pt}_{1} / \mathrm{CeO}_{2}$ catalyst. J. Am. Chem. Soc. 141, 17995-17999 (2019).

27. Preuster, P. et al. Liquid organic hydrogen carriers (LOHCs): toward a hydrogen-free hydrogen economy. Acc. Chem. Res. 50, 74-85 (2017).

28. Modisha, P. M. et al. The prospect of hydrogen storage using liquid organic hydrogen carriers. Energy Fuels. 33, 2778-2796 (2019).

29. Solowey, D. P. et al. A new and selective cycle for dehydrogenation of linear and cyclic alkanes under mild conditions using a base metal. Nat. Chem. 9, 1126-1132 (2017).

30. Nakaya, Y. et al. Active, selective, and durable catalyst for alkane dehydrogenation based on a well-designed trimetallic alloy. ACS Catal. 10 5163-5172 (2020)

31. Okada, Y. et al. Development of dehydrogenation catalyst for hydrogen generation in organic chemical hydride method. Int. J. Hydrog. Energy 31, 1348-1356 (2006)

32. Chen, J. et al. Surface engineering protocol to obtain an atomically dispersed $\mathrm{Pt} / \mathrm{CeO}_{2}$ catalyst with high activity and stability for $\mathrm{CO}$ oxidation. ACS Sustain. Chem. Eng. 6, 14054-14062 (2018).

33. Ravel, B. et al. ATHENA, ARTEMIS, HEPHAESTUS: data analysis for X-ray adsorption spectroscopy using IFEFFIT. J. Synchrotron Radiat. 12, 537-541 (2005).

34. Setthapun, W. et al. Genesis and evolution of surface species during Pt atomic layer deposition on oxide supports characterized by in situ XAFS analysis and water-gas shift reaction. J. Phys. Chem. C. 114, 9758-9771 (2010).

35. Schildhauer, T. et al. The equilibrium constant for the methylcyclohexane-toluene system. J. Catal. 198, 355-358 (2001),

36. Liu, J. C. et al. Theoretical understanding of the stability of single-atom catalysts. Natl Sci. Rev. 5, 638-641 (2018).

37. Resasco, J. et al. Uniformity is key in defining structure-function relationships for atomically dispersed metal catalysts: the case of $\mathrm{Pt} / \mathrm{CeO}_{2}$. J. Am. Chem. Soc. 142, 169-184 (2019).

38. Jiang, $\mathrm{Z}$. et al. Stabilizing platinum atoms on $\mathrm{CeO}_{2}$ oxygen vacancies by metalsupport interaction induced interface distortion: mechanism and application. Appl. Catal. B. 278, 119304 (2020).

39. Kariya, N. et al. Efficient hydrogen production using cyclohexane and decalin by pulse-spray mode reactor with Pt catalysts. Appl. Catal. A 247, 247-259 (2003).

40. Zhang, $\mathrm{Z}$. et al. Thermally stable single atom $\mathrm{Pt} / \mathrm{m}-\mathrm{Al}_{2} \mathrm{O}_{3}$ for selective hydrogenation and CO oxidation. Nat. Commun. 8, 1-10 (2017).

41. Chesters, M. A. et al. The infrared spectrum of cyclohexane adsorbed on Pt (111). Spectrochim. Acta A 46, 1011-1016 (1990).

42. Holgado, J. P. et al. Study of $\mathrm{CeO}_{2}$ XPS spectra by factor analysis: reduction of $\mathrm{CeO}_{2}$. Appl. Surf. Sci. 161, 301-315 (2000).

43. Bêche, E. et al. Ce $3 \mathrm{~d}$ XPS investigation of cerium oxides and mixed cerium oxide (CexTiyOz). Surf. Interface Anal. 40, 264-267 (2008).

44. Maslakov, K. I. et al. XPS study of ion irradiated and unirradiated $\mathrm{CeO}_{2}$ bulk and thin film samples. Appl. Surf. Sci. 448, 154-162 (2018).

45. Mullins, D. R. et al. Electron spectroscopy of single crystal and polycrystalline cerium oxide surfaces. Surf. Sci. 409, 307-319 (1998).

46. Kato, S. et al. Quantitative depth profiling of $\mathrm{Ce}^{3+}$ in $\mathrm{Pt} / \mathrm{CeO}_{2}$ by in situ highenergy XPS in a hydrogen atmosphere. Phys. Chem. Chem. Phys. 17, 5078-5083 (2015). 
47. Han, K. N. et al. Development of $\mathrm{Pt} / \mathrm{TiO}_{2}$ nanohybrids-modified SWCNT electrode for sensitive hydrogen peroxide detection. Sensors Actuators B: Chem. 174, 406-413 (2012).

48. Osaki, J. et al. Selective loading of platinum or silver cocatalyst onto a hydrogen-evolution photocatalyst in a silver-mediated all solid-state Z-scheme system for enhanced overall water splitting. RSC Adv. 9, 41913-41917 (2019).

49. Qi, K. et al. Single atom is not alone: metal-support interactions in singleatom catalysis. Mater. Today 40, 173-192 (2020).

50. van Deelen, T. W. et al. Control of metal-support interactions in heterogeneous catalysts to enhance activity and selectivity. Nat. Catal. 2, 955-970 (2019).

51. Allen, A. E. et al. Synergistic catalysis: a powerful synthetic strategy for new reaction development. Chem. Sci. 3, 633-658 (2012).

52. Blakely, D. W. et al. The dehydrogenation and hydrogenolysis of cyclohexane and cyclohexene on stepped (high miller index) platinum surfaces. J. Catal. 42, 181-196 (1976).

53. Coperet, C. et al. Silica-supported, narrowly distributed, subnanometric PtZn particles from single sites with high propane-dehydrogenation performance. Chem. Sci. 11, 1549-1555 (2020).

54. Dai, Y. et al. Recent progress in heterogeneous metal and metal oxide catalysts for direct dehydrogenation of ethane and propane. Chem. Soc. Rev. $\mathbf{5 0}$ 5590-5630 (2021).

55. Liu, J. et al. Highly-dispersed zinc species on zeolites for the continuous and selective dehydrogenation of ethane with $\mathrm{CO}_{2}$ as a Soft Oxidant. ACS Catal. 11, 2819-2830 (2021).

56. Bratlie, K. M. et al. Platinum nanoparticle shape effects on benzene hydrogenation selectivity. Nano Lett. 7, 3097-3101 (2007).

57. Wang, Y. et al. Pure hydrogen production by partial dehydrogenation of cyclohexane and methylcyclohexane over nanotube-supported Pt and Pd catalysts. Energy Fuels 18, 1429-1433 (2004).

58. Boufaden, N. et al. Dehydrogenation of methylcyclohexane to toluene over partially reduced silica-supported Pt-Mo catalysts. J. Mol. Catal. A: Chem. $\mathbf{4 2 0}$ 96-106 (2016).

\section{Acknowledgements}

This work was supported by the Hydrogen Materials Advanced Research Consortium (HyMARC), established as part of the Energy Materials Network by the U.S. Department of Energy (DOE), Office of Energy Efficiency and Renewable Energy, Fuel Cell Technologies Office, under Contract Number DE-AC02-05CH11231. This research used resources of the Advanced Light Source, which is a DOE Office of Science User Facility under the same contract. Work by L.C., P.V., Y.L., J.G. D.P., and J.S., was performed as part of a User Project at The Molecular Foundry of the Lawrence Berkeley National Laboratory, which is supported by the Office of Science of the U.S. Department of Energy also under the same contract. The Sandia National Laboratory is a multi-mission laboratory managed and operated by National Technology and Engineering Solutions of Sandia, LLC, a wholly owned subsidiary of Honeywell International, Inc., for the U.S. Department of Energy's National Nuclear Security Administration under Contract No. DE-NA-0003525. We thank Jeng-Lung Chen and Chih-Wen Pao in National Synchrotron Radiation Research Center (NSRRC) for the measurement and analysis of Pt
XANES spectra. For computational resources, we thank National Energy Research Scientific Computing Center (NERSC) and High-Performance Computing Services (HPCS) at Lawrence Berkeley National Laboratory.

\section{Author contributions}

L.C. performed the catalyst preparation and catalyst testing under the supervision of J.S. and G.A.S. K.H. and L.C. carried out the catalytic hydrogenation testing and NMR measurement of catalytic products. Z.Q. performed in situ FTIR and APXPS measurements. S.Z. carried out the TEM, XRD, and XPS measurements. Y.-S.L. and J.G. performed the XANES measurement and data analysis. D.P. and P.V. performed the calculations for the mechanism of cyclohexane dehydrogenation L.C, V.S., M.D.A., L.Z. M.S., and J.S. conceived the idea. D.P., A.G.S., and J.S. supervised the project. All authors contributed to the data analysis and drafting of this manuscript.

\section{Competing interests}

The authors declare no competing interests.

\section{Additional information}

Supplementary information The online version contains supplementary material available at https://doi.org/10.1038/s41467-022-28607-y.

Correspondence and requests for materials should be addressed to David Prendergast, Gabor A. Somorjai or Ji Su.

Peer review information Nature Communications thanks the anonymous reviewer(s) for their contribution to the peer review of this work.

Reprints and permission information is available at http://www.nature.com/reprints

Publisher's note Springer Nature remains neutral with regard to jurisdictional claims in published maps and institutional affiliations.

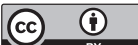

Open Access This article is licensed under a Creative Commons Attribution 4.0 International License, which permits use, sharing, adaptation, distribution and reproduction in any medium or format, as long as you give appropriate credit to the original author(s) and the source, provide a link to the Creative Commons license, and indicate if changes were made. The images or other third party material in this article are included in the article's Creative Commons license, unless indicated otherwise in a credit line to the material. If material is not included in the article's Creative Commons license and your intended use is not permitted by statutory regulation or exceeds the permitted use, you will need to obtain permission directly from the copyright holder. To view a copy of this license, visit http://creativecommons.org/ licenses/by/4.0/.

(c) The Author(s) 2022 